\title{
RoboSTEAM - A Challenge Based Learning Approach for integrating STEAM and develop Computational Thinking
}

\author{
Miguel Á. Conde, Camino \\ Fernández \\ University of León \\ León, Spain \\ \{mcong,cferll\}@unileon.es
}

\author{
Susana Celis-Tena \\ IES Eras de Renueva \\ León, Spain \\ susanact@ieserasderenueva.org
}

\author{
Jonny Alves \\ Colégio Internato dos Carvalhos \\ Pedroso, Portugal \\ jonny.alves@cic.pt
}

\author{
María-João Ramos \\ Agrupamento de Escolas Emídio \\ Garcia \\ Bragança, Portugal \\ f331aepq@gmail.com
}

\author{
José Gonçalves, José Lima \\ Instituto Politécnico de Bragança \\ Bragança, Portugal \\ \{goncalves, jllima\}@ipb.pt
}

\author{
Daniela Reimann \\ Karlsruhe Institute of Technology \\ Karlsruhe, Germany \\ daniela.reimann@kit.edu
}

\author{
Ilkka Jormanainen \\ University of Eastern Finland \\ Joensuu, Finland \\ ilkka.jormanainen@uef.fi
}

\author{
Francisco J. García Peñalvo \\ University of Salamanca \\ Salamanca, Spain \\ fgarcia@usal.es
}

\begin{abstract}
We live in a digital society that needs new better prepared professionals for the new challenges and opportunities provided by the ICT. Students must learn how to deal with all the issues that emerge in this new context. They should acquire computational thinking skills by integrating STEAM, however this needs for changes in current learning curricula and also new learning approaches. RoboSTEAM project deals with this issue by the application of a Challenge Based Learning approach that uses Robotics and Physical Devices. One of the problems found during the project is the complexity of the application of a Challenge Based Learning approach due to the special needs of each educational institution. Given this situation the present work presents provides a flexible definition of challenge and describes also samples regarding how to use them.

Permission to make digital or hard copies of all or part of this work for personal or classroom use is granted without fee provided that copies are not made or distributed for profit or commercial advantage and that copies bear this notice and the full citation on the first page. Copyrights for components of this work owned by others than the author(s) must be honored. Abstracting with credit is permitted. To copy otherwise, or republish, to post on servers or to redistribute to lists, requires prior specific permission and/or a fee. Request permissions from Permissions@acm.org.

TEEM'19, October 16-18, 2019, León, Spain

(C) 2019 Copyright is held by the owner/author(s). Publication rights licensed to ACM.

ACM ISBN 978-1-4503-7191-9/19/10 ..\$15.00

https://doi.org/10.1145/3362789.3362893
\end{abstract}

\section{CCS CONCEPTS}

- Applied computing $\rightarrow$ Education $\bullet$ Applied computing $\rightarrow$ Robotics $\cdot$ Social and professional topics $\rightarrow$ Computational thinking $\bullet$ Social and professional topics $\rightarrow$ K12 Education

\section{KEYWORDS}

Robotics, Physical Devices, Computational Thinking, STEAM , Challenge Based Learning, Schools Education.

\section{ACM Reference format:}

Miguel Á. Conde, Camino Fernández, Jonny Alves, María João Alves, Susana Celis, José Gonçalves, José Lima, Daniela Reimann, Ilkka Jormanainen and Francisco J. García-Peñalvo. 2018. RoboSTEAM Definition of a Challenge Based Learning Approach for integrating STEAM and develop Computational Thinking. In Proceedings of the Seventh International Conference on Technological Ecosystems for Enhancing Multiculturality (TEEM 2019) (León, Spain, October 16-18, 2019), ACM, New York, NY, USA, 7 pages. https://doi.org/10.1145/3362789.3362893

\section{Introduction}

Digital society has changed our daily lives, the way we access to the information, the way we interact with others, the way we 
develop our work, etc. We live in a digital landscape and professionals should be prepared to provide the better solutions for this changeable context. This means, that students need to be ready for this reality, they should address the new issues that emerge in the digital society, should know the new information sources, new devices, new concepts, etc. That is, they should develop skills in accordance with the new society requirements, (skills related with ICT) in order to guarantee their employability $[1,2]$.

With this in mind the problem is how to facilitate the students developing such ICT knowledge. That is, they need to develop skills like critical thinking, problem-solving, collaboration, communication and creativity [3-5]. A knowledge that together with other technical skills make possible the development of what is known as "Computational Thinking".

Computational Thinking (also known as CT) could be understood as "it is the study of computers and algorithmic processes including their principles, their hardware and software design, their applications, and their impact on society" [6] , it "involves solving problems, designing systems, and understanding human behavior, by drawing on the concepts fundamental to computer science"[7]. The development of CT is especially relevant in pre-university education $[1,8]$.

However, developing CT is not easy specially because the students requires developing such skills from an early age, something that use to be linked to STEM (Science, Technology, Engineering, \& Mathematics) education. These disciplines that have shown to be necessary in order to have more efficient workers in our digital society $[9,10]$. However, integrating and fostering STEM or STEAM (if we include the creativity component) in our current educational landscape is very complex. This is because it is not easy to summarize all this knowledge in a set of subjects without an associated loss of quality, and it cannot be focused only on some subjects or degrees [1]. New learning approaches are required and in this sense Project [11] or Problem Based Learning [12] could be an interesting possibility. However, RoboSTEAM project aims to go beyond these methodologies, looking for more flexible approaches such as Challenge Based Learning (CBL) [13]. Moreover, as the students require not only to know how to solve a problem, but to see the solution and even touch it, a very interesting possibility to engage the students with this methodology is the use of Physical Devices and Robotics (PD\&R) [14-17].

RoboSTEAM will define a methodology and a set of tools that will help learners to develop computational thinking by using/programming PD\&R in pre-university education stages. The project will also improve teacher education, providing them with a framework for easy STEAM integration in different educational contexts by providing guidelines for good practices and lessons learned adapted to different contexts. All these products will have been tested in different countries and crossvalidated in different higher education institutions [18].

In order to do so the project consortium includes eight institutions, five Higher education Institutions and three schools. The universities are: Universidad de León (ULE), Instituto
Politécnico de Bragança (IPB), Karlsruher Institut Fuer Technologie (KIT), University of Eastern Findland University (UEF); and Universidad de Salamanca (USAL). The schools are: Colégio Internato dos Carvalhos (CIC); Agrupamento de Escolas Emídio Garcia (AEEG); and IES - Eras de Renueva (IER). It should be pointed out that the UEF will participate in the project also as a school, because this institution, represented by the same PIC, include both the university and primary and secondary schools. The idea is to test the methodology and tools in these different institutions so it was possible to know if the transnationality of the project approach.

However, the application of a CBL methodology is not easy and can be different depending on the context. For instance: it is different the application of such methodology in contexts such as the Spanish than in the Nordic European countries. This means that is necessary to apply CBL in a flexible way and in order to do show the present paper presents a description of the challenge concept, a possible template to apply it and the main issues found.

The rest of the paper is structured as follows, next section presents what Challenge Based Learning is. Section 3, describes the challenge concept. Section 4 describes the challenge template and some samples of project challenges. Finally, some conclusions are posed.

\section{Challenge Based Learning}

CBL is a flexible methodology that encourages students to leverage the technology they use in their daily lives to solve realworld problems [13]. CBL is a collaborative methodology. It is going to involve the students' groups, but also other peers, teachers, experts, parents, etc. in order to solve a real problem. A $\mathrm{CBL}$ approach require to propone to the students a big idea, this idea will be discussed in order to find some main questions. The students analyze the questions and define a challenge. The challenge is addressed by the students in a collaborative way and involving people from their educational contexts and from the outside [19]. Some authors identify 3 phases in a CBL methodology [20]:

- Engage. Through a process of Essential Questioning the Learners move from an abstract Big Idea to a concrete and actionable Challenge.

- Investigate. All Learners plan and participate in a journey that builds the foundation for Solutions and addresses academic requirements.

- $\quad$ Act. Evidence-based Solutions are developed, implemented with an authentic audience, and then evaluated based on their results.

Some samples of the application of CBL could be [13, 19, 2126]. From these experiments and other it is possible to describe some advantages of this methodologies [27]:

- $\mathrm{CBL}$ provide to the students a deeper understanding of different topics and the possibility to learn how to analyze the problems in order to pose the better solutions. 
- $\mathrm{CBL}$ involve learners both in the definition and solution of a problem.

- $\quad$ CBL promotes collaborative working between students from different disciplines in order to solve a problem. This collaboration goes beyond their classmates, but includes also parents, teachers, researchers, experts, etc. This collaboration could help them in their professional development.

- $\mathrm{CBL}$ connects the student with the real world in order to address the challenges.

- $\quad$ CBL promote the development of communication skills by using social and media tools.

However also previous works have shown some drawbacks in the methodology:

- Global projects are often away from the specific contents of academic subjects [23].

- Traditional assessment systems can be a problem for students, because they may be more focused on assessments than on learning [12].

- Most of the CBL experiments cannot be easily associated to a specific subject in academic contexts. They used to be applied to CBL specific designed subjects or to master projects [25].

- Students' perception about this approach is not clear because not all the experiments have indicators to evaluate this [26].

- The participation of people with different roles may cause difficulties for students that should adapt their way to work to this situation [23].

- The results of the global projects are typically obtained when the academic year has finished [21].

- There is wide choice of tools to use in CBL experiences so evaluation is not easy [27].

Some of these drawbacks are also present in the RoboSTEAM project. RoboSTEAM aims to carry out two pilot stages. The first phase includes piloting in 5 schools with students from 12 to 16 applying the methodology and later to carry a pilot stage exchanging challenges and tools. In order to check if the same solutions and challenges can be applied in different socioeconomic context. At this moment, this piloting is being designed and one of the most relevant issue found is to understand what a Challenge is, and how to define challenges to be applied in different schools, with time and students background constraints.

\section{Challenge concept}

One of the main problems we found during the project is the heterogeneity in the institutions involved in the project and the problems to understand the challenge concept. Given this context, it is necessary to describe the challenge concept with different granularity levels, so it can be adapted to the special needs of each institution. In this case the project team decides to apply the concept of Challenge, Mina-Challenge and Nano-Challenge proposed by Nichols et al. [20]. In the next subsections these concepts will be commented.

\subsection{Challenge}

It works posing to students a big idea, they should discuss about it and define some main questions about this idea, from these questions a challenge is proposed. Students should address the challenge looking for a collaborative solution that involves their peers, teachers, experts, etc. After this, the solution, will be assessed [19]. "Standard Challenges are longer (one month and longer) and allow considerable latitude for the Learners. Working together, the Learners identify and investigate Big Ideas, develop Challenges, do extensive investigation across multiple disciplines and take full ownership of the process. The Framework is used from start to finish, including implementation and evaluation of the Solution in an authentic setting." [20]

Although in the literature there is not a clear description about how many hours the students employ to these types of challenges per day we are considering 4 hours per day, 5 days per week and 4 weeks per month. This means that it should comprise 80 working hours, from which around 40-60 should be at class and 20-40 is personal work of the student. Examples of standard challenges [28]:

- $\quad$ Big Idea: Gender Equality

- Main question: How do we achieve gender equality?

- Challenge: Build a culture of gender equity!

- Later we will have some guiding questions, research, act and reflect.

\subsection{Mini-challenge}

Are not so big as a standard challenge and increase the level of choice and responsibility of a nano-challenge, typical duration is around 2-4 weeks. These challenges allow learners "to start with a Big Idea and work through the entire framework. The research depth and the reach of their Solutions increases and the focus can be content specific or multidisciplinary. Taking a "show me what you can do" perspective, Mini Challenges are good for intense learning experiences that stretch the Learners and prepare them for longer Challenges"[20]. Regarding duration with 4 hours per day, 5 days per week model we can talk about a minimum of 40 hours per mini challenges, which $20-30$ should be at class and 1020 are devoted to students' personal work. Several minichallenges could be the base for a standard challenge.

\subsection{Nano-challenge}

"Nano Challenges are shorter in length, focus on a particular content area or skill, have tight boundaries and are more teacher directed. The Learners typically start with the Challenge without identifying a Big Idea or Essential Question. The process includes the Investigation and Act phases, but at a significantly lower level of intensity and often stop short of implementation with an external audience. Typically, Nano Challenges are used as scaffolding leading to more significant Challenges or during longer Challenges to address specific concepts" [20]. That is, nano-challenge will be our minimum unit to build challenges, it is more oriented to a Project based learning approach, it could involve external people but it is not necessary. Regarding the 
RoboSTEAM - A Challenge Based Learning Approach for integrating STEAM and develop Computational Thinking

number of hours required by it we are talking between 6-10 hours of classes and 4-6 of students work. Several nano-challenges can be used to address a mini-challenge.

\section{Challenge template and Sample}

In order to facilitate the definition of a Challenge, Minichallenge and Nano-challenge by the project consortium a template was provided to them. It includes information about each of this challenges levels.

In Table 1 it is possible to see the Challenge template. It includes fields for the author identification and the challenge title, a field for the challenge description, the goals and the evaluation.

Table 1: Challenge Template

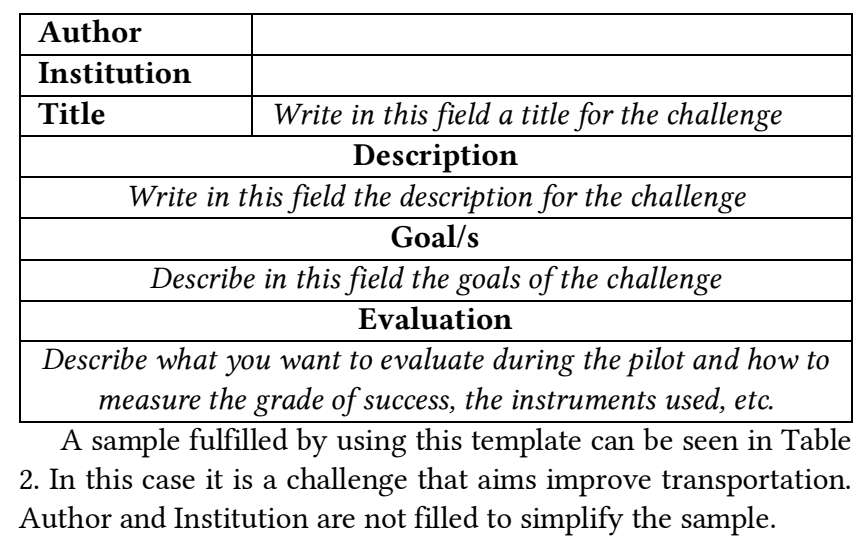

Table 2: Challenge Sample

\begin{tabular}{|c|c|}
\hline Title & Improve Transportation \\
\hline \multicolumn{2}{|r|}{ Description } \\
\hline \multicolumn{2}{|c|}{$\begin{array}{l}\text { The use of vehicles that employ fossil fuels has a great impact in } \\
\text { the environment. Propose approaches to reduce this impact }\end{array}$} \\
\hline \multicolumn{2}{|c|}{ Goal/s } \\
\hline - & $\begin{array}{l}\text { Improve environment. } \\
\text { Define the proper research question/s for the problem } \\
\text { you are dealing with. } \\
\text { Look for successful transportation solutions. } \\
\text { Built a possible approach. } \\
\text { Ask your parents, experts and peers looking for the } \\
\text { best solution. }\end{array}$ \\
\hline \multicolumn{2}{|r|}{ Evaluation } \\
\hline $\begin{array}{r}\text { Durin } \\
- \\
- \\
-\end{array}$ & $\begin{array}{l}\text { his challenge we can assess: } \\
\text { Time employed to solve the challenge } \\
\text { Degree of success producing a solution } \\
\text { Number of people involved in the challenge (students, } \\
\text { experts, parents, etc.) } \\
\text { Perception about STEEM } \\
\text { Assessment of STEM perception and CT skills before } \\
\text { and after the challenge }\end{array}$ \\
\hline
\end{tabular}

TEEM 2019, October 2019, León, Spain

The challenge could be divided in Mini-Challenge and Table 3 template should be used for the description.

Table 3: Mini-Challenge Template

\begin{tabular}{|c|c|}
\hline Auth & \\
\hline \multicolumn{2}{|c|}{ Institution } \\
\hline Title & Write in this field a title for the michallenge \\
\hline \multicolumn{2}{|c|}{ Research question or problem addressed } \\
\hline \multicolumn{2}{|c|}{$\begin{array}{l}\text { Describe the research question or problem addressed by this } \\
\text { Mini-Challenge }\end{array}$} \\
\hline \multicolumn{2}{|c|}{ Description } \\
\hline \multicolumn{2}{|c|}{ Write in this field the description for the Mini-Challenge } \\
\hline \multicolumn{2}{|c|}{ Goal/s } \\
\hline \multicolumn{2}{|c|}{ Describe in this field the goals of the Mini-Challenge } \\
\hline \multicolumn{2}{|c|}{$\begin{array}{l}\text { Evaluation } \\
\end{array}$} \\
\hline \multicolumn{2}{|c|}{$\begin{array}{l}\text { Describe what you want to evaluate during the pilot and how to } \\
\text { measure the grade of success, the instruments used, etc. }\end{array}$} \\
\hline
\end{tabular}

Table 4. shows an example of Mini-challenge for the previous challenge.

\section{Table 4: Mini-Challenge Sample}

\begin{tabular}{|c|c|}
\hline Title & Use mobile robots to improve transportation \\
\hline \multicolumn{2}{|r|}{ Research question or problem addressed } \\
\hline \multicolumn{2}{|c|}{$\begin{array}{l}\text { Can we employ mobile robots to reduce the transportation } \\
\text { impact in the environment? }\end{array}$} \\
\hline \multicolumn{2}{|c|}{ Description } \\
\hline \multicolumn{2}{|c|}{$\begin{array}{l}\text { The use of vehicles that employ fossil fuels has a great impact in } \\
\text { the environment. A possible solution to address this problem in } \\
\text { controlled environments can be the use of mobile robots. Think } \\
\text { about how to employ mobile robots to reduce the environmental } \\
\text { impact in transportation }\end{array}$} \\
\hline \multicolumn{2}{|c|}{ Goal/s } \\
\hline & $\begin{array}{l}\text { Study mobile robots } \\
\text { Study possible ways to apply mobile robots to improve } \\
\text { the environment } \\
\text { Explore the scenarios were mobile robots can be } \\
\text { applied } \\
\text { Built a possible approach based on mobile robots } \\
\text { Ask your parents, experts and peers looking for the } \\
\text { best solution. }\end{array}$ \\
\hline \multicolumn{2}{|r|}{ Evaluation } \\
\hline \multicolumn{2}{|c|}{$\begin{array}{l}\text { Describe what you want to evaluate during the pilot and how to } \\
\text { measure the grade of success, the instruments used, etc. }\end{array}$} \\
\hline & $\begin{array}{l}\text { Time employed to solve the challenge } \\
\text { Degree of success producing a solution that employ } \\
\text { mobile robots } \\
\text { Number of mobile robots used } \\
\text { Type and number of issues related with mobile robots } \\
\text { navigation solved } \\
\text { Number of people involved in the challenge (students, } \\
\text { experts, parents, etc.) }\end{array}$ \\
\hline
\end{tabular}


- Perception about STEEM

- $\quad$ Assessment of STEM perception and CT skills before and after the challenge

Table 5: Nano-Challenge Sample

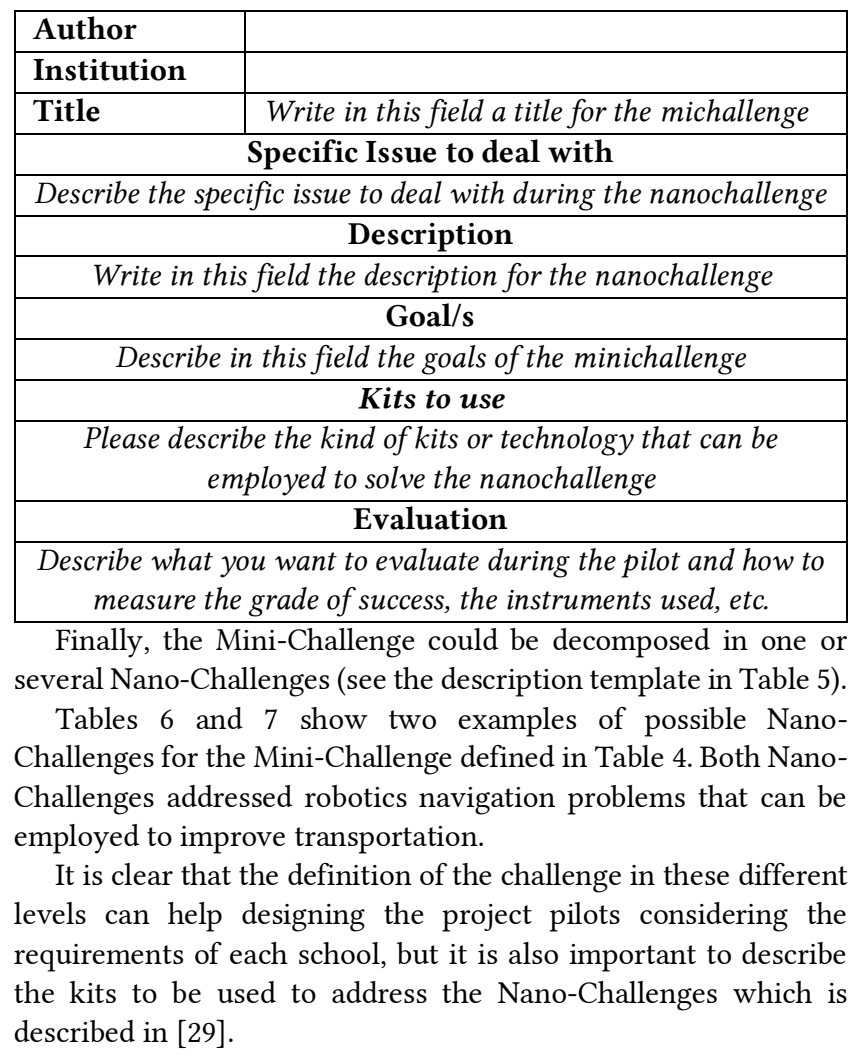

\section{Conclusions}

The development of CT skills and the integration of STEAM is a critical issue in our current educational landscape. The traditional learning plans and activities cannot easily integrate them. In this situation new learning approaches are necessary, and RoboSTEAM posed one of them.

RoboSTEAM project aims developing CT and integrating STEM by the application of a CBL approach that uses PD\&R. However, it is not easy, several issues emerging while designing the pilots. Such as:

- The subject where the pilot is going to take place. Something that depends in each school (some are related to technology, some to arts, some have mixed profiles, etc.)

- The number of hours to apply to the methodology. Depending on the country it is mandatory to teach the content planned for a specific subject, so it is necessary to fit in the CBL approach with the subject goals and schedule. Some partners will be able to employ several days, other only some hours. This have been addressd with the description of the different challenge types.

- Understanding the challenge concept is not easy. We have tried to overcome this by clarifying the challenge concept.

- Depending on the students' profile and technological background, tools to address the challenges should be adapted. The idea is to use robotics kits, but it is necessary to support the students to use them properly, so kits so be well described.

All this complexity is currently being dealt by RoboSTEAM project and the project team should continuous working on it during the next project activities. The piloting results will be also published.

Table 6: Nano-Challenge Sample - Robot following lines

\begin{tabular}{|c|c|}
\hline Title & $\begin{array}{l}\text { Follow lines with a mobile robot to facilitate } \\
\text { autonomous navigation }\end{array}$ \\
\hline \multicolumn{2}{|r|}{ Specific Issue to deal with } \\
\hline \multicolumn{2}{|c|}{ Use or built a robot that was able to follow a line } \\
\hline \multicolumn{2}{|c|}{$\begin{array}{l}\text { Description } \\
\end{array}$} \\
\hline \multicolumn{2}{|c|}{$\begin{array}{l}\text { The use of vehicles that employ fossil fuels has a great impact in } \\
\text { the environment. A possible solution to address this problem in } \\
\text { controlled environments can be the use of mobile robots. } \\
\text { However, a successful use of mobile robots with transport } \\
\text { proposes should explore the navigation problems and one of the } \\
\text { most common is how to use a robot to follow a line. }\end{array}$} \\
\hline \multicolumn{2}{|c|}{ Goal/s } \\
\hline & $\begin{array}{l}\text { Study mobile robots } \\
\text { Study navigation issues in mobile robots } \\
\text { Study possible ways facilitate that a mobile robot } \\
\text { follow a line } \\
\text { Explore the scenarios were mobile robots can be } \\
\text { applied } \\
\text { Built a possible approach of a mobile robot that } \\
\text { follows a line } \\
\text { Ask your parents, experts and peers looking for the } \\
\text { best solution. }\end{array}$ \\
\hline \multicolumn{2}{|r|}{ Kits to use } \\
\hline \multicolumn{2}{|c|}{ It is possible to use mRobot } \\
\hline \multicolumn{2}{|c|}{ Evaluation } \\
\hline \multicolumn{2}{|c|}{$\begin{array}{l}\text { Describe what you want to evaluate during the pilot and how to } \\
\text { measure the grade of success, the instruments used, etc. }\end{array}$} \\
\hline & $\begin{array}{l}\text { Time employed to solve the challenge } \\
\text { Degree of success using or building a robot that follow } \\
\text { a line } \\
\text { Robot accuracy following the line } \\
\text { Number of mobile robots used } \\
\text { Number of people involved in the challenge (students, } \\
\text { experts, parents, etc.) } \\
\text { Perception about STEEM } \\
\text { Assesment of STEM skills and CT skills before and } \\
\text { after the challenge }\end{array}$ \\
\hline
\end{tabular}


RoboSTEAM - A Challenge Based Learning Approach for integrating STEAM and develop Computational Thinking

\section{Table 7: Nano-Challenge Sample - Robot Avoiding Obstacles}

\begin{tabular}{|c|c|}
\hline Title & $\begin{array}{l}\text { Avoid obstacles with a mobile robot to facilitate } \\
\text { autonomous navigation }\end{array}$ \\
\hline \multicolumn{2}{|r|}{ Specific Issue to deal with } \\
\hline \multicolumn{2}{|c|}{ Use or built a robot that was able to avoid obstacles } \\
\hline \multicolumn{2}{|c|}{$\begin{array}{ll}\text { Description } \\
\end{array}$} \\
\hline \multicolumn{2}{|c|}{$\begin{array}{l}\text { The use of vehicles that employ fossil fuels has a great impact in } \\
\text { the environment. A possible solution to address this problem in } \\
\text { controlled environments can be the use of mobile robots. } \\
\text { However, a successful use of mobile robots with transport } \\
\text { proposes should explore the navigation problems and one of } \\
\text { them is to avoid obstacles. }\end{array}$} \\
\hline \multicolumn{2}{|c|}{ Goal/s } \\
\hline- & $\begin{array}{l}\text { Study mobile robots } \\
\text { Study navigation issues in mobile robots } \\
\text { Study possible ways to facilitate that a mobile robot } \\
\text { follow avoid an obstacle } \\
\text { Explore the scenarios were mobile robots can be } \\
\text { applied } \\
\text { Built a possible approach of a mobile robot that avoid } \\
\text { obstacles } \\
\text { Ask your parents, experts and peers looking for the } \\
\text { best solution. }\end{array}$ \\
\hline \multicolumn{2}{|r|}{ Kits to use } \\
\hline \multicolumn{2}{|c|}{ It is possible to use mRobot } \\
\hline \multicolumn{2}{|c|}{ Evaluation } \\
\hline \multicolumn{2}{|c|}{$\begin{array}{l}\text { Describe what you want to evaluate during the pilot and how to } \\
\text { measure the grade of success, the instruments used, etc. }\end{array}$} \\
\hline & $\begin{array}{l}\text { Time employed to solve the challenge } \\
\text { Degree of success using or building a robot that avoids } \\
\text { obstacles } \\
\text { Time required to complete navigate through an } \\
\text { scenario with obstacles } \\
\text { Number of mobile robots used } \\
\text { Number of people involved in the challenge (students, } \\
\text { experts, parents, etc.) } \\
\text { Perception about STEEM } \\
\text { Assessment of STEM perception and CT skills before } \\
\text { and after the challenge }\end{array}$ \\
\hline
\end{tabular}

\section{ACKNOWLEDGMENTS}

This paper is supported by ROBOSTEAM Erasmus+ KA201 Project with reference 2018-1-ES01-KA201-050939

\section{REFERENCES}

[1] Francisco José García-Peñalvo and Antònio José Mendes. 2018. Exploring the computational thinking effects in pre-university education. Computers in Human Behavior $\quad 80(2018 / 03 / 01 /), \quad 407-411$ DOI:http://dx.doi.org/https://doi.org/10.1016/j.chb.2017.12.005

[2] Lev Manovich. 2013. Software takes command. A\&C Black.

[3] Katerina Ananiadou and Magdalean Claro. 2009. 21st century skills and competences for new millennium learners in OECD countries.
[4] A. Balanskat and K. Engelhardt. 2015. Computing our future. Computer programming and coding Priorities, school curricula and initiatives across Europe.

[5] Marilyn Binkley, Ola Erstad, Joan Herman, Senta Raizen, Martin Ripley, May Miller-Ricci, and Mike Rumble. 2012. Defining twenty-first century skills. In Assessment and teaching of 21st century skills Springer, 17-66.

[6] Allen Tucker, Fadi Deek, Jill Jones, Dennis Mccowan, Chris Stephenson, and Anita Verno. 2003. A model curriculum for K-12 computer science. Final Report of the ACM K-12 Task Force Curriculum Committee, CSTA.

[7] Jeannette M Wing. 2006. Computational thinking. Communications of the ACM 49, 3, 33-35.

[8] Vicki Allan, Valerie Barr, Dennis Brylow, and Susanne Hambrusch. 2010 Computational thinking in high school courses. In Proceedings of the Proceedings of the 41st ACM technical symposium on Computer science education (Milwaukee, Wisconsin, USA2010). ACM, 1734395, 390-391. DOI:http://dx.doi.org/10.1145/1734263.1734395.

[9] Francisco José García-Peñalvo, Daniela Reimann, and Christiane Maday. 2018 Introducing Coding and Computational Thinking in the Schools: The TACCLE 3 - Coding Project Experience. In Computational Thinking in the STEM Disciplines: Foundations and Research Highlights, M.S. Khine Ed. Springer International Publishing, Cham, 213-226. DOI:http://dx.doi.org/10.1007/978-3319-93566-9 11.

[10] European-Commission/Eacea/Eurydice. 2018. The European Higher Education Area in 2018: Bologna Process Implementation Report. Publications Office of the European Union.

[11] Phyllis C. Blumenfeld, Elliot Soloway, Ronald W. Marx, Joseph S. Krajcik, Mark Guzdial, and Annemarie Palincsar. 1991. Motivating Project-Based Learning Sustaining the Doing, Supporting the Learning. Educational Psychologist 26, 3 4 (1991/06/01), 369-398. DOI:http://dx.doi.org/10.1080/00461520.1991.9653139.

[12] John R. Savery and Thomas M. Duffy. 1995. Problem-Based Learning: An instructional model and its constructivist framework. Educational Technology $35,5$.

[13] L. Johnson and S. Adams. 2011. Challenge Based Learning: The Report from the Implementation Project. The New Media Consortium.

[14] Soumela Atmatzidou and Stavros Demetriadis. 2016. Advancing students computational thinking skills through educational robotics: A study on age and gender relevant differences. Robotics and Autonomous Systems 75, 661-670.

[15] M. Merdan, W. Lepuschitz, G. Koppensteiner, and R. Balogh. 2017. Robotics in Education - Research and Practices for Robotics in STEM Education. Springer International Publishing.

[16] Erin Cejka, Chris Rogers, and Merredith Portsmore. 2006. Kindergarten robotics: Using robotics to motivate math, science, and engineering literacy in elementary school. International Journal of Engineering Education 22, 4, 711.

[17] Marina Umaschi Bers, Louise Flannery, Elizabeth R. Kazakoff, and Amanda Sullivan. 2014. Computational thinking and tinkering: Exploration of an early childhood robotics curriculum. Computers \& Education 72(2014/03/01/), 145157. DOI:http://dx.doi.org/https://doi.org/10.1016/j.compedu.2013.10.020.

[18] European-Comission. 2019. RoboSTEAM Project Description.

[19] Apple-Inc. 2009. Challenge Based Learning - Take action and make a difference US.

[20] Mark Nichols, K Cator, and M Torres. 2016. Challenge Based Learning Guide. Digital Promise, Redwood City, CA.

[21] Á. Fidalgo-Blanco, M. L. Sein-Echaluce, and F. J. García-Peñalvo. 2016 Integration of the methods $\mathrm{CBL}$ and $\mathrm{CBI}$ for their application in the management of cooperative academic resources. In Proceedings of the 2016 International Symposium on Computers in Education (SIIE) (13-15 Sept. 2016 2016). 1-6. DOI:http://dx.doi.org/10.1109/SIIE.2016.7751849.

[22] Nelson Baloian, Kay Hoeksema, Ulrich Hoppe, and Marcelo Milrad. 2006. Technologies and Educational Activities for Supporting and Implementing Challenge-Based Learning. In Education for the 21st Century - Impact of ICT and Digital Resources: IFIP 19th World Computer Congress, TC-3, Education, August 21-24, 2006, Santiago, Chile, D. Kumar and J. Turner Eds. Springer US, Boston, MA, 7-16. DOI:http://dx.doi.org/10.1007/978-0-387-34731-8_2.

[23] Whitney Brooke Gaskins, Jeffrey Johnson, Cathy Maltbie, and Anant Kukreti. 2015. Changing the Learning Environment in the College of Engineering and Applied Science Using Challenge Based Learning. International Journal of Engineering Pedagogy 5, 1, 33-41.

[24] Td Giorgio and Sp Brophy. 2001. Challenge-based learning in biomedical engineering: A legacy cycle for biotechnology. In Proceedings of the ASEE Annual Conference Proceedings (2001)

[25] J. Malmqvist, K.K. Rådberg, and U. Lundqvist. 2015. Comparative Analysis of Challenge-Based Learning Experiences. In Proceedings of the 11th International CDIO Conference (Chengdu, Sichuan, P.R. China2015).

[26] Catalina Marin, Jace Hargis, and Cathy Cavanaugh. 2013. iPad Learning Ecosystem: Developing Challenge-Based Learning Using Design Thinking. Turkish Online Journal of Distance Education 14, 2.

[27] Oie-Tec-Monterrey. 2016. Aprendizaje basado en retos. Tecnológico de Monterrey, Monterrey, Nuevo León, México. 
[28] Digital-Promise. 2018. Big Idea: Gender Equality.

[29] José Gonçalves, Jose Lima, Laiany Suganuma, Caio Rafael, Vitor Felipe, Thadeu Brito, and Miguel Conde. 2019. Educational Robotics Summer Camp at IPB: A
Challenge based learning case study. In Proceedings of the Seventh International Conference on Technological Ecosystems for Enhancing Multiculturality (TEEM'19) (León2019). ACM. 